\title{
Role of Platelet Rich Plasma in Treatment of Diabetic Foot Ulcers
}

\author{
Aymen Salem, Ahmad M. Tawfik \\ Faculty of Medicine, Zagazig University, Zagazig, Egypt \\ Email: tawfik2carotid@yahoo.com
}

Received 12 May 2016; accepted 13 June 2016; published 16 June 2016

Copyright (C) 2016 by authors and Scientific Research Publishing Inc.

This work is licensed under the Creative Commons Attribution International License (CC BY). http://creativecommons.org/licenses/by/4.0/

c) (i) Open Access

\begin{abstract}
Objectives: The aim of this study is to compare between the platelet rich plasma and balanced moist dressing as regards the healing rate in chronic non ischemic diabetic foot ulcers. Patients and Method: From Feb. 2014 till May 2015, 73 patients from the attendees to Zagazig university hospitals were selected to our study. 2 groups were created, one for PRP (platelet rich plasma) and the other for balanced moist dressing. Frequent registration for the number of healed ulcers was done every week. Results: By the end of the $3^{\text {rd }}$ week almost all the ulcers in the PRP group were healed. But the other group needed about $8^{\text {th }}$ weeks for the same results. Conclusion: PRP seems to be an attractive choice in management of chronic diabetic ulcers provided that there is good blood supply and proper offloading was done.
\end{abstract}

\section{Keywords}

Ulcer, Platelet, Plasma, Offloading and Moist Dressing

\section{Introduction}

Foot ulcers are one of the major draw backs of diabetes. About $15 \%$ of all diabetic patients may complain from these ulcers. 88\% of all leg amputations were related to diabetic foot ulcers [1]. Few decades ago diabetic foot ulcers were treated by vacuum-assisted closure, high voltage pulsed current electrical stimulation and hyperbaric oxygen. Some biological therapies were used in ulcers treatment with improvement of the time of wound healing [2].

In the recent studies, growth factors from Platelet Rich Plasma (PRP) used for enhancing wound healing were compared to conventional therapies. Wound healing started by release of local growth factors which attracted stem cells into wound. PRP decreased cytokine release, and increased capillary growth. PRP has also some antimicrobial effects against Candida albicans, MRSA and E. coli [3]. 
This study aimed to access the role of the usage of autologous PRP in diabetic patient type 2 with resistant foot ulcers.

\section{Patients and Methods}

From Feb. 2014 till May 2015, 73 patients from the attendees to Zagazig university hospitals were selected to our study according to the following inclusion and exclusion criteria.

The inclusion criteria were patients with DM type II with planter foot ulcers not healed for more than 3 months, intact distal pulsation and ulcers grade 1 and grade 2 according to Wagner grading system Figure 1.

The exclusion criteria were patients with liver cell failure, renal impairment, heart failure, sever cardiomyopathy, bleeding or platelet disorders, malignancies or short life expectations, peripheral vascular disease, major lower limb amputations, low immunity or corticosteroid therapy and ulcers (grade 3, grade 4 and grade 5).

Full medical and surgical history taking, general assessment, vascular examination and neurological assessment were done for all patients. Laboratory investigations (pre-operative), $\mathrm{X}$ ray foot, arterial duplex and culture from the ulcers were done routinely. All patients signed the consent. This study approved by Ethical and Medical Committee in our faculty.

On outpatient basis debridement was done for all ulcers, optimization of the patients' general conditions, broad spectrum antibiotics first then based on culture were described.

All the ulcers were divided in to 2 groups, group (A) including 42 ulcers for PRP and group (B) including 31 ulcers for routine dressing according to our protocol (balanced moist dressing). The size of ulcers was recorded before treatment and every week till complete healing. Offloading for all cases by total contact cast was done.

For PRP preparation $25 \mathrm{~mL}$ of the patient blood was collected. The blood was centrifuged at $2000 \mathrm{rpm}$ for 5 min to obtain plasma. Then, this plasma was centrifuged at $3000 \mathrm{rpm}$ for another $5 \mathrm{~min}$ to collect platelets at the (37 Celsius). Platelets were diluted in $5 \mathrm{~mL}$ plasma to form PRP and the rest of plasma now considered as Platelet Poor Plasma (PPP). Both were activated by Calcium chloride which leads to gel formation for dressing, and PPP was stored for injection Figure 2. Ulcers were dressed by fibrin gel in the first day. After 3 days daily till the end of the first week injection with activated PPP Was done. If after 2 weeks, still there is no healing, the procedure can be repeated again Figure 3. Data was collected and tabulated and statistical analysis was done with p value recorded as a significance indicator.

\section{Results}

In our prospective study, 73 patients were enrolled, 42 patients for group (A) and 31 for group (B). The ages were between $56 \mathrm{y}$ and $61 \mathrm{y}$ in group (A) but in group (B) the ages were between $51 \mathrm{y}$ and $62 \mathrm{y}$. All the cases were type II diabetes. No significant association between the pre-existing medical condition and the distribution among the groups (Table 1).

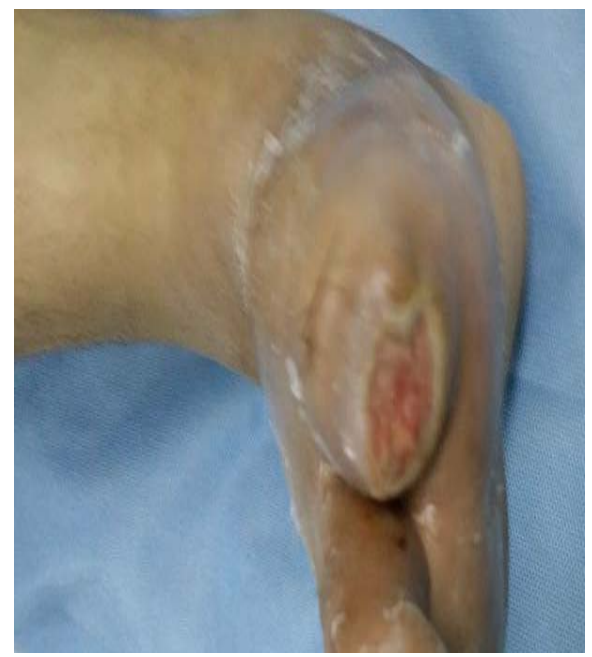

Figure 1. Fore foot ulcer. 


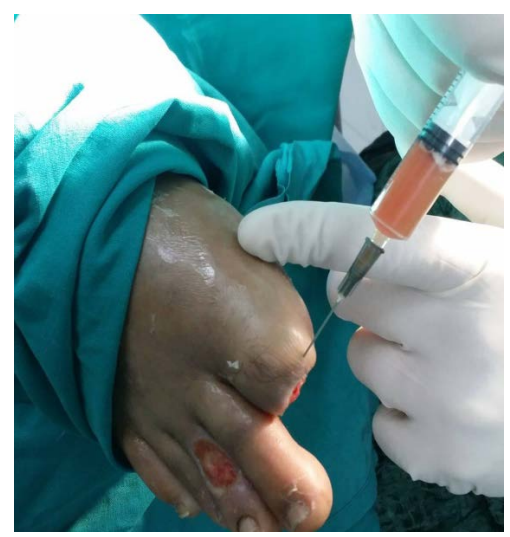

Figure 2. Injection of PRP.

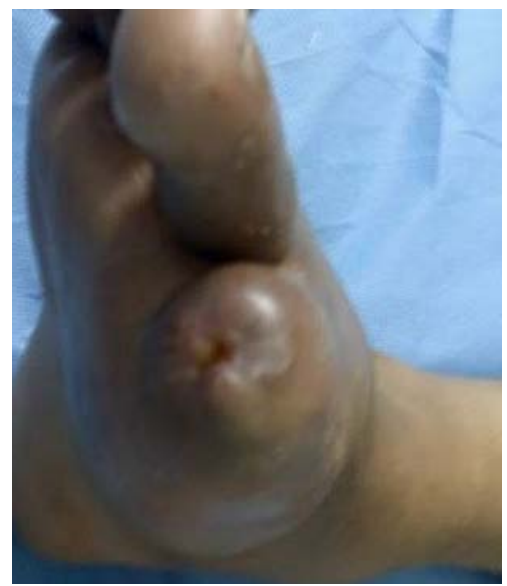

Figure 3. Healed ulcer.

Table 1. Past medical history.

\begin{tabular}{|c|c|c|c|}
\hline & Group (A) & Group (B) & $\mathrm{P}$ value \\
\hline Age (mean) in years & $58.6 \pm 2.7$ & $56.9 \pm 5.6$ & 0.08 \\
\hline Sex (male:female) Male\% & 19:23 (45.2\%) & $14: 17(45.1 \%)$ & 0.99 \\
\hline Age of diabetes in years & $11.2 \pm 1.8$ & $9.4 \pm 2.9$ & 0.002 \\
\hline Hypertensive patients (N, \%) & 37 (88\%) & $24(77.4 \%)$ & 0.26 \\
\hline History of stroke (N, \%) & $6(14.2 \%)$ & $8(25.8 \%)$ & 0.08 \\
\hline History of minor Amputations at the same foot or contralateral foot $(\mathrm{N}, \%)$ & $5(11.9 \%)$ & $6(19.3 \%)$ & 0.14 \\
\hline Number of patients on insulin versus oral hypoglycemic & 39:3 (92.8\%) & $26: 5(83.8 \%)$ & 0.49 \\
\hline History of ischemic heart disease (N, \%) & $4(9.5 \%)$ & $3(3.2 \%)$ & 0.07 \\
\hline
\end{tabular}

As regard the ulcers size, in group (A) the size was about $2.3 \mathrm{~cm}$ but in group (B) the size was $2.5 \mathrm{~cm}$. Most of ulcers were in the mid foot in both groups. Few cases were healed before the study but recurrent again and enrolled in the study Table 2 and Graph 1.

By the end of the $3^{\text {rd }}$ week most of ulcers in group $(A)$ were healed except one ulcer was infected and major amputation was done. In this moment only 6.4\% of ulcers in group (B) were healed. The ulcers of group (B) were healed by the end of the $8^{\text {th }}$ week except 3 ulcers, 2 of them were infected and major amputation was done, the last ulcer was missed from follow up before complete healing Table 3 and Table 4, Graph 2. 
History of recurrence at the same site

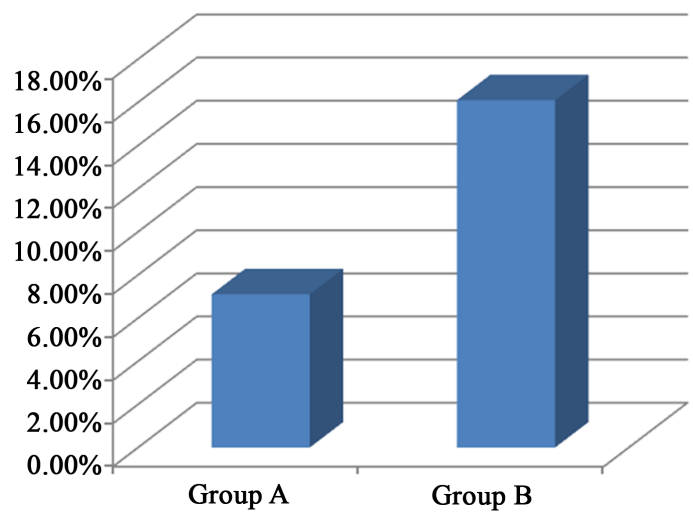

History of recurrence at the same site

1. History of recurrence. Y represent percentage of recurrent cases.

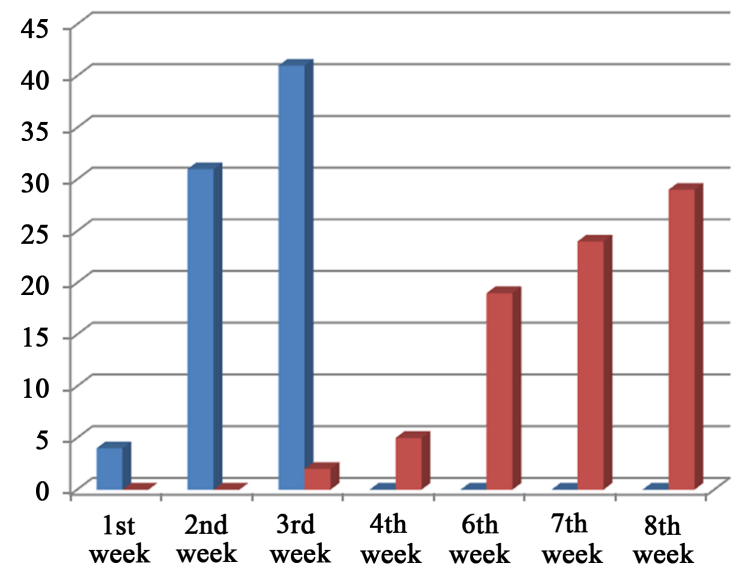

- Group (A) healed ulcer

- Group (B) healed ulcer

Graph 2. Rate of healing. Y number of healed ulcers.

Table 2. Clinical presentation.

\begin{tabular}{cccc}
\hline & Group (A) & Group (B) & P value \\
\hline Size of the ulcers in $\mathrm{cm}^{2}$ & $2.3 \pm 0.4 \mathrm{~cm}^{2}$ & $2.5 \pm 0.6 \mathrm{~cm}^{2}$ & 0.11 \\
Age of the ulcers in months & $3.2 \pm 0.2 \mathrm{~m}$ & $3.4 \pm 0.5 \mathrm{~m}$ & 0.07 \\
& 13 fore foot & 19 fore foot & 16 mid foot \\
Site of the ulcers & 10 hind foot & 7 hind foot & 0.84 \\
History of recurrence at the same site & 3 cases (7.1\%) & 5 cases (16.1\%) & 0.66 \\
\hline
\end{tabular}

Table 3. Rate of healing.

\begin{tabular}{cccc}
\hline Times & Group (A) Number of healed ulcers & Group (B) Number of healed ulcers & P value \\
\hline $1^{\text {st }}$ week & $4(9.5 \%)$ & $0(0 \%)$ & 0.007 \\
$2^{\text {nd }}$ week & $31(73.8 \%)$ & $0(0 \%)$ & 0.00 \\
$3^{\text {rd }}$ week & $41(97.6 \%)$ & $2(6.4 \%)$ & 0.00 \\
$4^{\text {th }}$ week & - & $5(16.1 \%)$ & 0.0001 \\
$6^{\text {th }}$ week & - & $19(61.2 \%)$ & 0.00 \\
$7^{\text {th }}$ week & - & $24(77.4 \%)$ & 0.00 \\
$8^{\text {th }}$ week & - & $29(93.5 \%)$ & 0.00 \\
\hline
\end{tabular}


Table 4. Rate of infections.

\begin{tabular}{cccc}
\hline & Group (A) & Group (B) & P value \\
\hline Number of infected cases & $1(2.3 \%)$ & $2(6.4 \%)$ & 0.12 \\
\hline
\end{tabular}

\section{Discussion}

One of the most common causes of ulcers is growth factor abnormality. Platelets are considered as a rich source of growth factors. PRP enhance wound healing by either barrier effect to prevent the bacterial invasion into the wound or the growth factors stimulate wound healing [4].

PDGF is one of growth factors was used alone for enhancing of the wound healing, but the application of PRP (with balanced amounts of growth factors) gives better result [5].

Most of publications apply PRP only on the wound but we apply both activated PRP and PPP. PRP enrich the wound by multiple growth factors for cell migrations and neo-angiogenesis while PPP contains nutrients for healing [6].

In our study among 73 ulcers, we compered between PRP and balanced moist dressing in our center for management of chronic non ischemic planter diabetic foot ulcers. By the end of the $3^{\text {rd }}$ week 41 cases were totally healed in PRP group while in the other group 2 ulcers only were healed. The other group was totally healed in $8^{\text {th }}$ week. This result was statically significant.

Saad et al. (2011) compared the results of both PRP and PPP on ulcer healing and showed that healing in PRP group was faster $(\mathrm{P}<0.005)$ than PPP [7].

Our results were agreed with Lone et al. (2014) who used PRP to treat DFUs. They showed that $62.85 \%$ patients developing granulation tissue by the end of second weeks and $77.78 \%$ patients reached $100 \%$ granulation at the end of the $3^{\text {rd }}$ week [8].

Also McAleer et al. (2006) reported the good results of PRP in chronic foot ulcers in a 57-year-old man [9]. Another study reported the synergistic effect of a both autologous adipose tissue and PRP in a case study of a diabetic 65-year-old male patient who had a foot ulcer since 3 years [10].

Scimeca et al. (2010) published the successful result for treatment of chronic plantar diabetic ulcer in a 49-year-old man using PRP [11]. A retrospective cohort of 599 patients with diabetic foot ulcers was published, and reported complete healing in $50 \%$ of patients undergoing PRP treatment and $41 \%$ of patients not treated with PRP [12].

\section{Conclusion}

Foot ulcers affect the quality of life n diabetic patients. In our study the results confirm that, the use of PRP and PPP increase ulcers healing rate. These results provided a promising method for ulcers treatment.

\section{Conflict of Interest}

No conflict of interest.

\section{References}

[1] Alvarsson, A., Sandgren, B., Wendel, C., Alvarsson, M. and Brismar, K. (2012) A Retrospective Analysis of Amputation Rates in Diabetic Patients: Can Lower Extremity Amputations Be Further Prevented? Cardiovascular Diabetology, 11, 18. http://dx.doi.org/10.1186/1475-2840-11-18

[2] Armstrong, G.D. and Lavery, A.L. (1998) Diabetic Foot Ulcers, Prevention, Diagnosis and Classification. American Family Physician, 57, 1325-1332.

[3] Cervelli, V., Gentile, P., Scioli, M.G., Grimaldi, M., Casciani, C.U., et al. (2009) Application of Platelet-Rich Plasma in Plastic Surgery: Clinical and in Vitro Evaluation. Tissue Engineering Part C, Methods, 15, 625-663. http://dx.doi.org/10.1089/ten.tec.2008.0518

[4] Kim, D.H., Kim, C.D., Lee, Y.H., Seo, Y.J., Lee, J.H. and Lee, Y. (2011) Can Platelet-Rich Plasma Be Used for Skin Healing? Evaluation of Effects of Platelet-Rich Plasma on Human Dermal Fibroblast. Annals of Dermatology, 23, 424431. http://dx.doi.org/10.5021/ad.2011.23.4.424

[5] Steed, D.L. (1995) Clinical Evaluation of Recombinant Human Platelet-Derived Growth Factor for the Treatment of 
Lower Extremity Diabetic Ulcers: The Diabetic Ulcer Study Group. Journal of Vascular Surgery, 21, 71-78. http://dx.doi.org/10.1016/S0741-5214(95)70245-8

[6] Cruciani, M., Lipsky, B.A., Mengoli, C. and de Lalla, F. (2013) Granulocyte-Colony Stimulating Factors as Adjunctive Therapy for Diabetic Foot Infections. The Cochrane Database of Systematic Reviews, 8, CD006810. http://dx.doi.org/10.1002/14651858.cd006810.pub3

[7] Saad Setta, H., Elshahat, A., Elsherbiny, K., Massoud, K. and Safe, I. (2011) Platelet-Rich Plasma versus Platelet-Poor Plasma in the Management of Chronic Diabetic Foot Ulcers: A Comparative Study. International Wound Journal, 8, 307-312. http://dx.doi.org/10.1111/j.1742-481X.2011.00797.x

[8] Lon, A.M., Zaroo, M.I., Laway, B.A., Pala, N.A., Bashir, S.A. and Rasool, A. (2014) PRP versus Conventional Dressings in the Management of Diabetic Foot Ulcers: A Prospective Case-Control Study. Diabetic Foot \& Ankle, 54, 671678.

[9] McAleer, J.P., Sharma, S., Kaplan, E.M. and Persich, G. (2006) Use of Autologous Platelet Concentrates in a Nonhealing Lower Extremity Wound. Advances in Skin \& Wound Care, 19, 354-363. http://dx.doi.org/10.1097/00129334-200609000-00010

[10] Margolis, D.J., Kantor, J. and Santanna, J. (2001) Effectiveness of Platelet Releasate for the Treatment of Diabetic Neuropathic Foot Ulcers. Diabetes Care, 24, 483-488. http://dx.doi.org/10.2337/diacare.24.3.483

[11] Scimeca, C.L., Bharara, M. and Fisher, K.T. (2010) Novel Use of Platelet-Rich Plasma to Augment Curative Diabetic Foot Surgery. Journal of Diabetes Science and Technology, 4, 1121-1126. http://dx.doi.org/10.1177/193229681000400510

[12] Everts, P.A., Brown Mahoney, C. and Hoffmann, J.J. (2006) Platelet-Rich Plasma Preparation Using Three Devices: Implications for Platelet Activation and Platelet Growth Factor Release. Growth Factors, 24, 165-171. http://dx.doi.org/10.1080/08977190600821327

\section{Submit or recommend next manuscript to SCIRP and we will provide best service for you:}

Accepting pre-submission inquiries through Email, Facebook, Linkedin, Twitter, etc

A wide selection of journals (inclusive of 9 subjects, more than 200 journals)

Providing a 24-hour high-quality service

User-friendly online submission system

Fair and swift peer-review system

Efficient typesetting and proofreading procedure

Display of the result of downloads and visits, as well as the number of cited articles

Maximum dissemination of your research work

Submit your manuscript at: http://papersubmission.scirp.org/ 